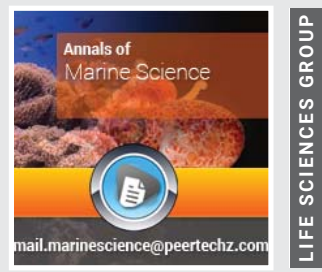

\title{
EPR dating of shells from Malhada Marsh, Rio de Janeiro, Brazil
}

\author{
MB Gomes ${ }^{1,2 *}$, LM Oliveira ${ }^{1,2}$, B Cortez ${ }^{1}$, MC D'Oca ${ }^{2}$, L \\ Tranchina ${ }^{3}$, E Tomarchio ${ }^{4}$, A Parlato ${ }^{4}$, JFD Chubaci ${ }^{5}, \mathbf{R}$ \\ Gennari ${ }^{5}$, RR Rocca ${ }^{6}$, F d'Errico ${ }^{7}$, S Sousa ${ }^{8}$, S Watanabe ${ }^{5}$ \\ and M Marrale ${ }^{2}$ \\ ${ }^{1}$ Nuclear and Energy Research Institute, University of São Paulo, Brazil \\ 2Department of Physics and Chemistry “Emilio Segrè", University of Palermo, Italy \\ ${ }^{3}$ Advanced Technologies Network (ATeN) Center, University of Palermo, Italy \\ ${ }^{4}$ Department of Engineering, University of Palermo, Italy \\ ${ }^{5}$ Physics Institute, University of São Paulo, Brazil \\ ${ }^{6}$ Marine Science Department, Federal University of São Paulo, Brazil \\ ${ }^{7}$ University of Pisa, Italy \\ ${ }^{8}$ Physics Department, Federal University of Aracaju, Brazil
}

Received: 01 November, 2019

Accepted: 28 January, 2020

Published: 29 January, 2020

*Corresponding author: Monise Brito Gomes, Nuclear and Energy Research Institute, University of São Paulo, São Paulo, Brazil, Tel: +55-11-3091-6990;

E-mail: monisebrito@usp.br

Keywords: Dating; EPR; Shell

https://www.peertechz.com

Check for updates

\begin{abstract}
The formation of the coastal plain of the Brazilian sea is mainly due to the fluctuation of relative sea level in the past. Armação dos Buzios or simply Buzios is a municipality in the microregion of lakes, in the state of Rio de Janeiro. In this region there is a lowland area about two meters above current sea level. This lowland area is also known as coastal plain of Una River. It is expected that during the Holocene period the sea level reached a maximum about 2.5 meters above the current level. During that time billions of mollusks lived and proliferated in the shallow waters around the coastal plain of the Una River. As they died their shells formed a layer in the soil including Malhada Marsh that belongs to the Una River plain. In this study, shells were collected from this region and dated using the techniques of Electronic Paramagnetic Resonance (EPR). Ages from $2480 \pm 130$ to $4490 \pm 270$ years were obtained. Radiocarbon dating were performed at the Beta Analytic Lab, USA for comparison with the EPR results. Shells ages obtained are compatible with geological data from the Holocene period relative to past sea level fluctuations.
\end{abstract}

\section{Introduction}

Electronic Paramagnetic Resonance spectroscopy studies paramagnetic species. To become paramagnetic, its atoms must have at least 1 unpaired electron, which may be naturally present, if the material is paramagnetic, the paramagnetic properties may result from the effect of radioactivity. The action of ionizing radiation on matter is capable to induce changes in the material's in the energy levels created prohibit bands by defects in the crystal, electronic structure. Electrons or holes may become trapped in the crystal lattice, creating radiation-induced paramagnetic species [1]. They form a signal that can be identified by EPR spectroscopy, whose intensity directly needs the amount of charges trapped in the crystal lattice, thus reflecting the dose absorbed by the material. In EPR spectroscopy, electromagnetic waves irradiate a sample and their absorption is measured. However, the waves will only be absorbed if a magnetic field is present simultaneously in the sample. Age can be provided by measuring the concentration of paramagnetic species present in a sample [2].

Every fossil sample is exposed to environmental ionizing radiation produced mainly by uranium, thorium, potassium, and cosmic rays over a long period. Although annual dose rates are not enough to cause lifetime problems to normal human 
beings, over thousands of years a dose of the order of 10Gy can be deposited in a certain material [3]. The older the sample is, the greater is the accumulated dose $\left(\mathrm{D}_{\mathrm{ac}}\right)$ and consequently the greater the amplitude of the EPR signal.

The estimate of the annual dose rate Dan is obtained by determining the concentrations (in $\mathrm{ppm}$ ) of the radioactive elements, ${ }^{238} \mathrm{U},{ }^{232} \mathrm{Th}$ and ${ }^{40} \mathrm{~K}$ present in the shells $\left(\mathrm{D}_{\text {int }}\right)$ and in the sediments surrounding the sample $\left(\mathrm{D}_{\text {ext }}\right)[4]$.

Shell was the material studied in the EPR measurements. Two marine shell samples were dated by Radiocarbon method at Beta Analytic Laboratory to compare with EPR shells dating. These shells were collected from the Malhada Marsh. This place as already mentioned is among the so-called situated in the municipality of Armação dos Buzios in the state of Rio de Janeiro, Brazil as shown in Figure 1. The theory says that in the Holocene period around 5500 and 4500 years B.P., sea level reached a maximum level of about $2.5 \mathrm{~m}$ above the current [5]. During that time billions of mollusks lived and proliferated in the shallow waters around the coastal plain of the Una River. As they died their shells formed a layer in the soil including Malhada Marsh that belongs to the Una River plain. Vestiges of marine shells in places that are a long distance from the sea, have aroused great interest from quaternary researchers, to correlate with fluctuations in sea level in this region of Brazil. We describe here our investigations using marine mollusk species, aimed at understand the fluctuation of sea level in the past, and to understand the ages as carried out using the technique of EPR and radiocarbon. Due to the historical importance of sea level variation in the past. Several works were published in the region of the present study[1,8,9].

\section{Materials and methods}

The materials to be dated by EPR method are shells collected from the wall of well in Figure 2 from Malhada Marsh. In this figure we can see that the wall of the well has three parts, one from the surface comprising sediments without shell, the second with a thickness of about $60 \mathrm{~cm}$ containing large number of shells and sediments. The third part contains only sediments without shells. In the period when the sea level reached about $2.5 \mathrm{~m}$ ( $0.5 \mathrm{~m}$ above the present one), billions of mollusks proliferated. Figure 3 shows this portion of shells wall. Close to the Malhada Marsh, there is a place called Reserva de Tauá. Inside of it a space (with extension of about $100 \mathrm{~m} \times 40 \mathrm{~m}$ ) full of shells is present shown in Figure 4 . We also collected shells from this place for dating. The Table 1 shows the depth at which each sample was collected horizontally with the PVC tubes.

A fragment shell was used to perform X-Ray Fluorescence (XRF) measurements. This technique allowed to investigate the composition of some chemical elements present in the shell. Nine different points of the shell fragment were analyzed.

Samples were chemically washed with acetic acid (with a concentration of $2.5_{\%(\mathrm{~V} / \mathrm{V})}$ followed by distilled water for washing. Then samples were grinded with agata sphere mortar grinder and sieved to retain grains of $80-180 \mu \mathrm{m}$. The retained grains were etched by $0.5 \%$ acetic acid for a few

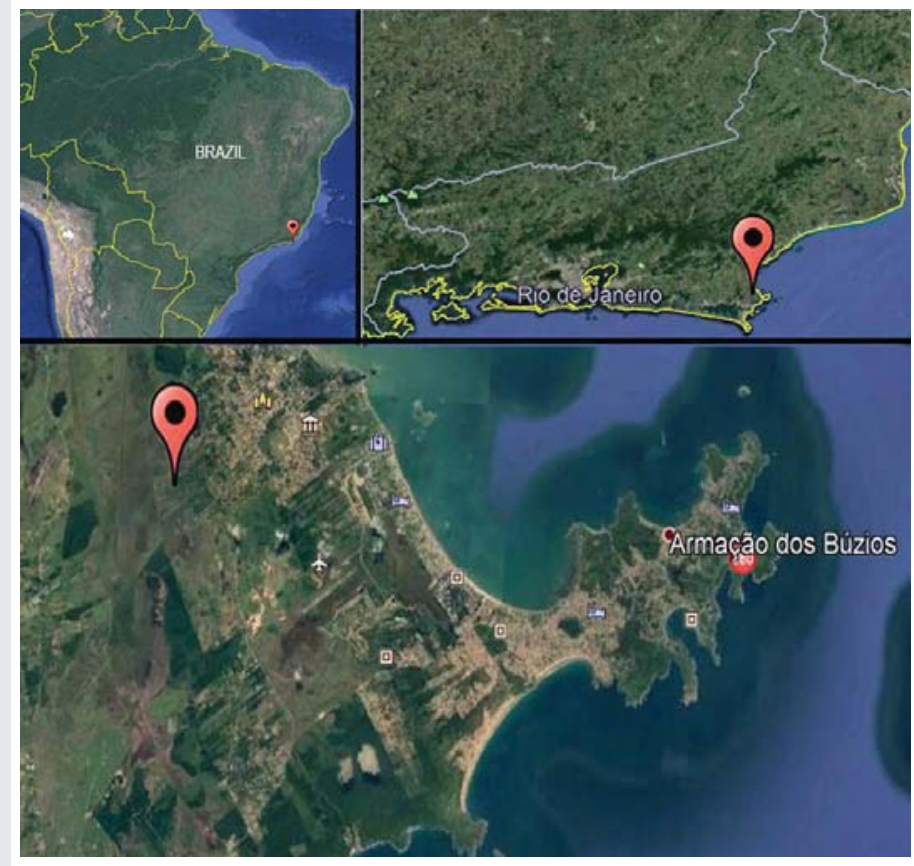

Figure 1: Map locating the Buzios and Malhada Marsh, Location where the shells were collected for dating the present study.

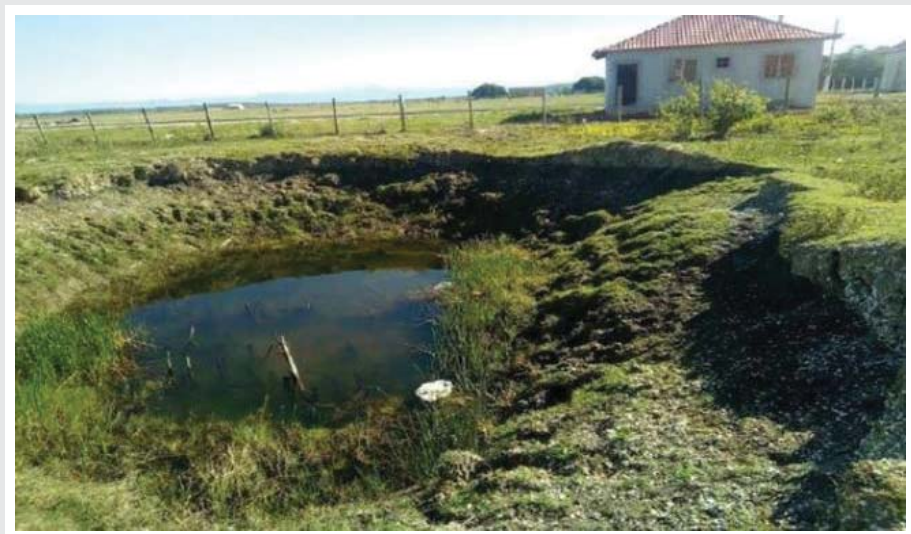

Figure 2: Location where the shells were collected from Açude (Açude is a well with water to help animals).

minutes to remove the surface defect the signal at $g=2.0002$ caused by the pressure in grinding [10,11]. Afterwards they were washed with distilled water and dried at a temperature of $40^{\circ} \mathrm{C}$. Each sample was divided into aliquots, approximately 300 to $500 \mathrm{mg}$ each, and were used for 11 irradiations between $10 \mathrm{~Gy}$ and $120 \mathrm{~Gy}$ for accumulated dose reconstruction. In our experiments irradiations with ${ }^{60} \mathrm{Co} \gamma$-photons were carried out at the IGS-3 irradiator in the Department of Engineering at the University of Palermo. One aliquot was not irradiated to obtain background dose during samples processing (Natural dose). After irradiation, each portion of shell powder was transferred to quartz tubes of $4 \mathrm{~mm}$ in diameter for EPR measurements. Shell grains with diameter smaller than $0.080 \mathrm{~mm}$ were used for crystalline structure analysis by X-ray diffraction (XRD). The crystalline phases of the shells were investigated by XRD technique using the LYNXEYE detector with 192 channels, with $\mathrm{Cu} \mathrm{K} \alpha$ radiation $(\lambda=1.5418 \AA)$, and the data was collected by scanning from $10^{\circ}$ to $90^{\circ}$ at room temperature. 
EPR measurements were performed at room temperature utilizing a pulsed EPR Bruker ELExysis E580 spectrometer. The EPR spectra were recorded at $9.8 \mathrm{GHz}$ (X-band) microwave frequency, $1 \mathrm{Mw}$ microwave power, field modulation of $0.1 \mathrm{mT}$ at $100 \mathrm{kHz}$.

The estimate of the annual dose rate Dan is obtained by determining the concentrations of the radioactive elements, ${ }^{238} \mathrm{U}$, ${ }^{232} \mathrm{Th}$ and of ${ }^{40} \mathrm{~K}$ present in the shells $\left(\mathrm{D}_{\text {int }}\right)$ and in the sediments surrounding the sample $\left(\mathrm{D}_{\text {ext }}\right)$. From these values, $\mathrm{D}_{\text {an }}$ can be calculated using the Table 4.5 of $\alpha-, \beta-$ and $\gamma$-dose of unit sample of ${ }^{238} \mathrm{U},{ }^{232} \mathrm{Th}$ and ${ }^{40} \mathrm{~K}$ from Ikeya [1]. The gamma spectrometry technique was used for the quantification of the radioisotopes present inside the shells and sediments. Gamma spectrometry measurements were performed on the shells to evaluate the contribution to the annual dose rate due to natural radioisotopes inside the shells themselves. To determine contribution to dose rate due to the sediments surrounding the sample $\left(D_{\text {ext }}\right)$, we separated approximately 20 grams of sediment

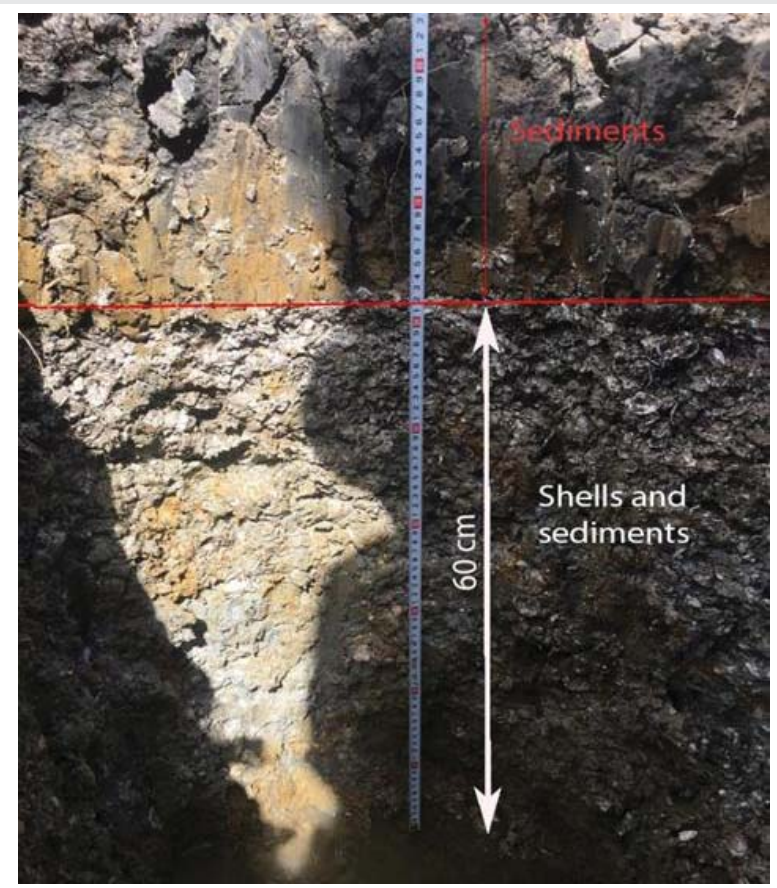

Figure 3: Portion of shells wall.

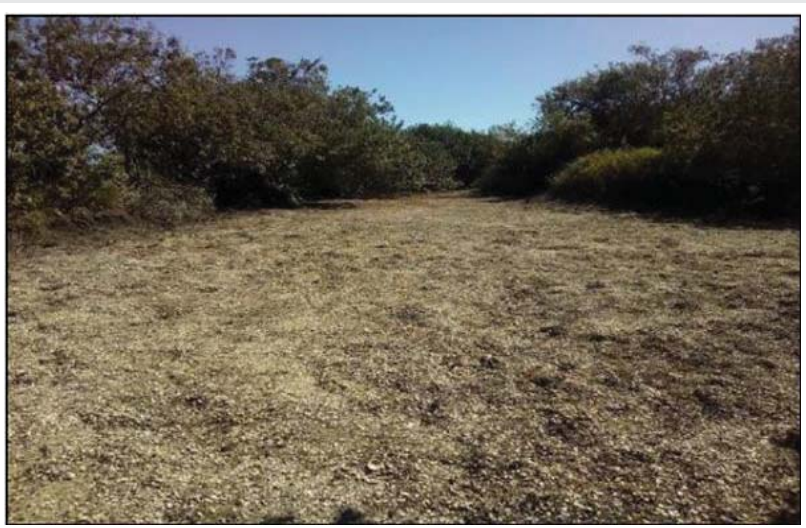

Figure 4: Portion of shells wall.
Table 1: Description of the samples collected for this study.

\begin{tabular}{|c|c|c|c|c|l|}
\hline Sample & Place & $\begin{array}{c}\text { Geographic } \\
\text { Coordinates: } \\
\text { Latitude }\end{array}$ & $\begin{array}{c}\text { Geographic } \\
\text { Coordinates: } \\
\text { Longitude }\end{array}$ & $\begin{array}{c}\text { Horizontal } \\
\text { depth }\end{array}$ & Type of samples \\
\hline PM3 & Açude & -22.754868 & -41.998245 & $\pm 70 \mathrm{~cm}$ & Shells and sediments \\
\hline PM2 & Açude & -22.754873 & -41.998201 & $\pm 50 \mathrm{~cm}$ & Shells and sediments \\
\hline PM1 & Açude & -22.724903 & -41.998195 & $\pm 20 \mathrm{~cm}$ & Shells and sediments \\
\hline RT5 & $\begin{array}{c}\text { Reserva de } \\
\text { Tauá }\end{array}$ & -22.754114 & -41.997975 & $\pm 25 \mathrm{~cm}$ & Shells and sediments \\
\hline RT3 & $\begin{array}{c}\text { Reserva de } \\
\text { Tauá }\end{array}$ & -22.754110 & -41.997971 & $\pm 15 \mathrm{~cm}$ & Shells and sediments \\
\hline RT2 & $\begin{array}{c}\text { Reserva de } \\
\text { Tauá }\end{array}$ & -22.754099 & -41.997970 & $\pm 10 \mathrm{~cm}$ & Shells and sediments \\
\hline
\end{tabular}

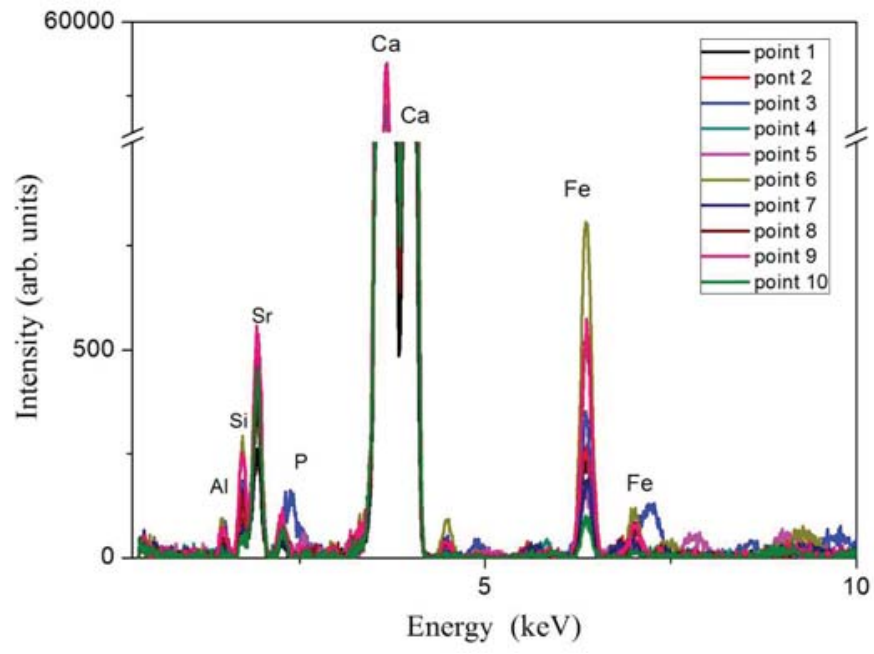

Figure 5: X-ray fluorescence spectrum of the shells.

in plastic pots for each sample and the concentrations (in ppm) of the radioactive elements, ${ }^{238} \mathrm{U},{ }^{232} \mathrm{Th}$, (in \%) ${ }^{40} \mathrm{~K}$ were obtained. In order to take into account the effect due to the presence of water, a correction with the equations (4.16) and (4.17) from Ikeya book is used [1]. To estimate the annual dose rate due to cosmic rays, the DRAC program was used, considering the geographic coordinates of the site [10].

Two shell samples (PM1 and PM3) were dated at the Beta Analytics Laboratory by the Accelerator Mass Spectrometry (AMS) method.

\section{Results and discussions}

The shells were analyzed to determine which different types of species were found in the collected site. The species Anomalocardia Brasiliana and Lucina Pectinata were found, both species are marine shells. The large amount of marine shells that exists in the place, is one of the evidences that, in the past, this region was immersed in the sea.

The XRF measurements of shells obtained were interpreted by the Artax software present on the instrumentation, estimating the characteristic X-ray intensities for the elements $\mathrm{Ca}, \mathrm{Fe}, \mathrm{Al}, \mathrm{Si}, \mathrm{Sr}$ and $\mathrm{P}$ (Figure 5). Important elements in the classification of the samples are related to their origin. It is important to identify the constituent elements in the shell to 
define sample preparation. The problem of manganese present inside the shell for performing EPR measurements since paramagnetic $\mathrm{Mn}_{2}{ }^{+}$masks radiation-induced radical signals. As can be seen from Figure 5, manganese is not present in our samples or there is not a significant amount that the XRF measurement could identify in our samples.

The XRD measurement of shell is shown in Figure 6 . Comparing the powder XRD pattern to the Match Program, all the peaks of the shells were identified as belonging to the principal phases of aragonite. The aragonite are less unstable than calcite and are converted to calcite at normal temperature and pressure [1]. Thermoluminescence dating requires sample heating, the thermal instability of aragonite makes the TL method not appropriate [11]. Which indicates that would be the best way of dating by the Electron Paramagnetic Resonance (EPR).

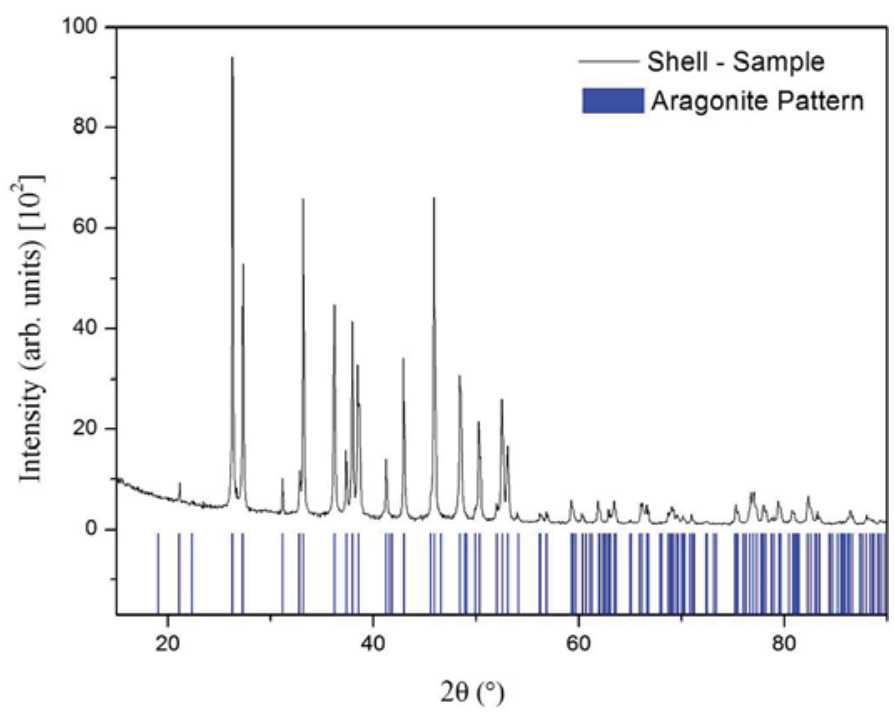

Figure 6: X-ray diffraction of the shell sample compared with the XRD pattern of aragonite.

The main information required for EPR dating is the annual dose rate $\left(D_{a n}\right)$. Measurements showed that the presence of natural radioisotopes inside the shell is negligible since the values measured were comparable with background natural radiation inside the laboratory. Based on this result the contribution to the annual dose rate due to internal radioisotopes $\left(D_{\text {int }}\right)$ can be neglected. The results of the evaluation of the annual dose rate found in the sediment around the shells are presented in Table 2.

The EPR spectrum of shell sample (aragonite) after chemical treatment and irradiated with $50 \mathrm{~Gy} \gamma$-dose is shown in Figure 7. In the analyzed shells the characteristic radical species of aragonite were found. The signal with $\mathrm{g}=\mathbf{2 . 0 0 5 7}$ is related to the freely rotating $\mathrm{SO}_{2}^{-}$, the $\mathrm{g}=\mathbf{2 . 0 0 3 1}$ is related to isotropic $\mathrm{SO}_{3}^{-}, \mathrm{g}=2.0007$ is related to freely rotating $\mathrm{CO}_{2}{ }^{-}$and $\mathrm{g}=1.9973$ is related to orthorhombic $\mathrm{CO}_{2}^{-}[1]$. The signal used for the dating is that at $\mathrm{g}=1.9973$ (Figure 7).
The EPR spectrum of an irradiated shell sample shows various signal component (among them the orthohombic one that will be used for the dating process) is shown in Figure 8. From the curves of the EPR signal vs dose values, the respective $D_{a c}$ values were estimated for each sample. Once the

Table 2: Concentration of $\mathrm{U}, \mathrm{Th}$ and $\mathrm{K}$ in the sediment samples used to calculate the annual dose of the samples.

\begin{tabular}{|c|c|c|c|c|c|c|}
\hline Sample & Th $(\mathbf{p p m})$ & $\mathbf{U}(\mathbf{p p m})$ & $\mathbf{K}(\%)$ & Water (\%) & Cosmic-ray & $\begin{array}{c}\mathbf{D}_{\text {an }} \\
\text { mG/year }\end{array}$ \\
\hline PM1 & $8.01 \pm 0.40$ & $1.28 \pm 0.08$ & $0.33 \pm 0.02$ & $16.2 \pm 0.8$ & 0.27 & $1.27 \pm 0.04$ \\
\hline PM2 & $10.06 \pm 0.45$ & $2.48 \pm 0.14$ & $0.45 \pm 0.03$ & $20.6 \pm 1.0$ & 0.27 & $1.64 \pm 0.05$ \\
\hline PM3 & $14.43 \pm 0.62$ & $2.18 \pm 0.13$ & $0.60 \pm 0.03$ & $28.7 \pm 1.4$ & 0.27 & $1.75 \pm 0.05$ \\
\hline RT2 & $10.27 \pm 0.49$ & $1.69 \pm 0.11$ & $0.39 \pm 0.03$ & $3.9 \pm 0.2$ & 0.27 & $1.76 \pm 0.05$ \\
\hline RT3 & $12.60 \pm 0.60$ & $2.00 \pm 0.14$ & $0.60 \pm 0.03$ & $6.0 \pm 0.3$ & 0.27 & $2.14 \pm 0.06$ \\
\hline RT5 & $15.31 \pm 0.70$ & $3.95 \pm 0.22$ & $0.52 \pm 0.03$ & $6.4 \pm 0.3$ & 0.27 & $2.70 \pm 0.07$ \\
\hline$D_{\text {an }}$ : annual dose. & & & & & \\
\hline
\end{tabular}

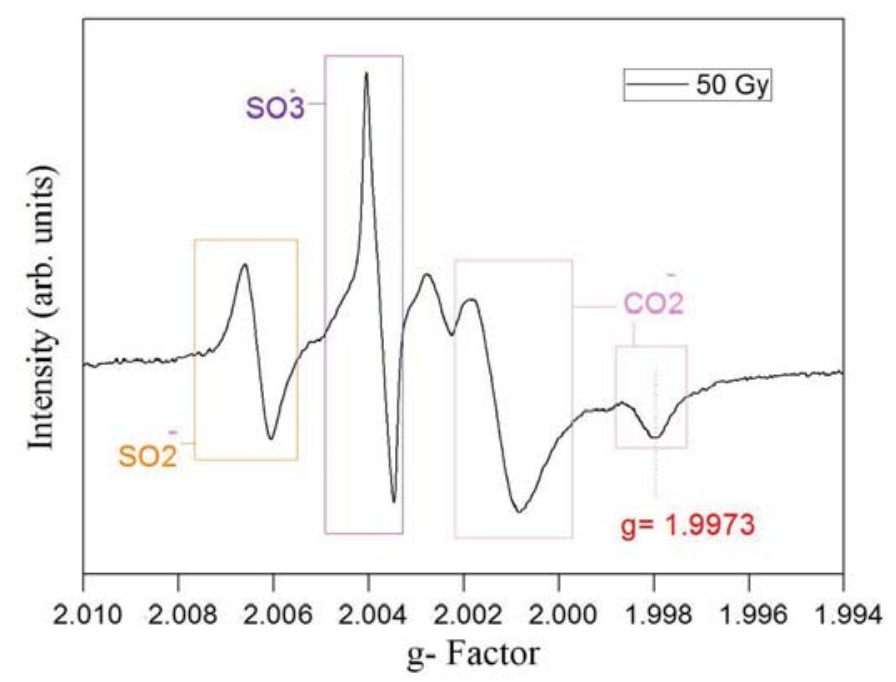

Figure 7: EPR spectrum of the shell sample PM after 60Co irradiation of 50 Gy.

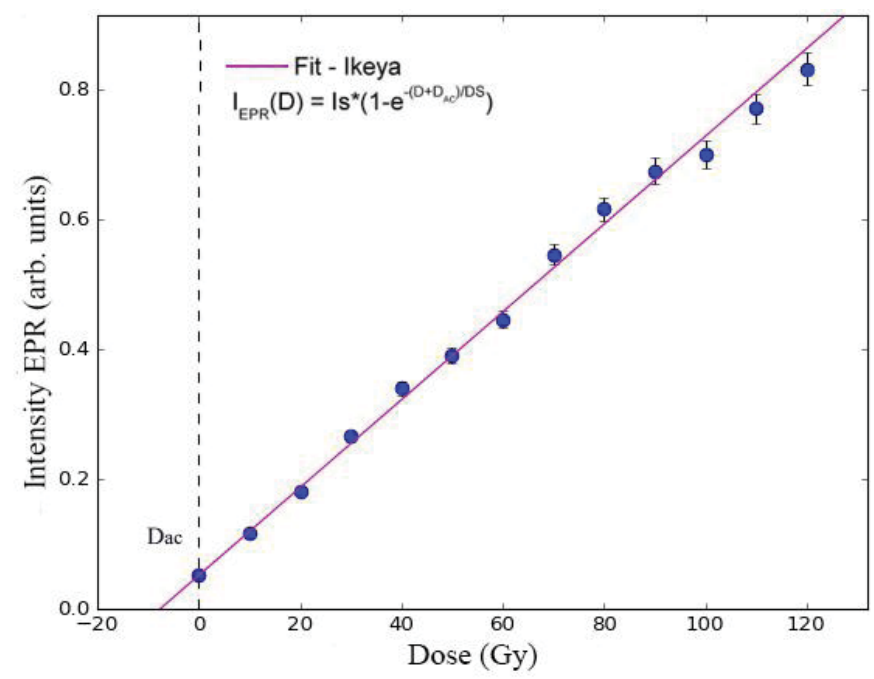

Figure 8: Growth curve in shell sample: experimental (blue ball), the best fit curve (pink line). The intersection of the best fit curves with the $x$-axis provides the values of the accumulated dose which are reported in each subplots.

Citation: Gomes MB, Oliveira LM, Cortez B, D'Oca MC, Tranchina L, et al. (2020) EPR dating of shells from Malhada Marsh, Rio de Janeiro, Brazil. Ann Mar Sci 4(1): 008-013. DOI: https://dx.doi.org/10.17352/ams.000018 
accumulated dose values and the annual dose rate values were obtained, the age of the shells can be obtained. The results are reported in Table 3 which shows the Accumulated Dose, Annual Dose Rate corrected considering the cosmic ray and water contribution and the age obtained. Radiocarbon dating by the accelerator mass spectrometry (AMS) were performed at the Beta Analytic Lab, USA for comparison with the EPR results (Table 4). The AMS and EPR techniques are different dating techniques and have different factors that influence the final reconstructed age. It is necessary to evaluate the difference of the parameters used to perform the dating. The AMS technique, can be used for radiocarbon dating of one milligram of carbon or even less. The small amount of sample required for analysis may allow for more selective sampling, but this involves that the results may depend on the part of the shell sampled which could have different concentration of carbon-14 with respect to other parts of the shell. Statistical errors are smaller in older samples.

Table 3: Ages obtained using EPR method.

\begin{tabular}{|c|c|c|c|}
\hline Sample & $\mathbf{D}_{\text {an }}$ (mGy/year) & $\mathbf{D}_{\text {ac }}($ Gy) & Age(years) \\
\hline PM1 & $1.27 \pm 0.04$ & $5.7 \pm 0.3$ & $4490 \pm 270$ \\
\hline PM2 & $1.64 \pm 0.05$ & $6.9 \pm 0.4$ & $4200 \pm 270$ \\
\hline PM3 & $1.75 \pm 0.05$ & $5.6 \pm 0.3$ & $3200 \pm 200$ \\
\hline RT2 & $1.76 \pm 0.05$ & $7.2 \pm 0.4$ & $4090 \pm 260$ \\
\hline RT3 & $2.14 \pm 0.06$ & $7.8 \pm 0.6$ & $3650 \pm 300$ \\
\hline RT5 & $2.70 \pm 0.07$ & $6.7 \pm 0.3$ & $2480 \pm 130$ \\
\hline
\end{tabular}

$D_{\text {an }}:$ annual dose; $D_{a c}:$ accumulated dose.

Table 4: Comparison between Radiocarbon and EPR ages.

\begin{tabular}{|c|c|c|}
\hline Sample & Conventional radiocarborn age (B.P.) & EPR age (years) \\
\hline PM1 & $5550 \pm 30$ & $4490 \pm 290$ \\
\hline PM3 & $5900 \pm 30$ & $3200 \pm 200$ \\
\hline
\end{tabular}

BP: Before present; EPR: Electron Paramagnetic Resonance.

It should be highlighting that it was not a unique shell that was used for experiments of radiocarbon dating and EPR dating. However, this last technique was used to compare shells located inside the same layer. Furthermore, in the case of AMS one shell is used whereas several shells of the same layer were used for EPR measurements. One factor that can affect the reconstructed age of the shell in the case of EPR method is the water content. Because water is an attenuating agent, the presence of water in the site where the shells were could protect the shell from external irradiation of the sediment around. The literature mentions the equation to correct this factor in calculating the annual dose. To perform this correction, the sediment was weighted before and after drying and the value of the mass difference was put into the equation [1]. However, it should be emphasized that the amount of water in the region is not the same for 365 days per year. We visited the region five times and of these five visits, two failed to collect samples because of the immense amount of water in the region that did not allow the shell layer to be found.
Ages of samples obtained by two different techniques (EPR and radiocarbon) are not close to each other within the experimental errors. However, considering the ages obtained from each technique, we can see that the shells belong to the Holocene period. In the literature it shows that ages obtained in this period contributed to the construction of the sea level variation curve in the past [5]. The shells are great evidence that there has been sea variation in the past in the studied region.

\section{Conclusion}

Shells were dated using EPR techniques. Shells were collected from (Açude and Reserva de Tauá) belonging to the Holocene period. Deposits of shells in the region show that there has been sea level variation in the past. At first, we believed that the shells of the first layer (PM3) were older and the third layer (PM1) was younger, as the shells died, they precipitated into layers. The EPR ages obtained did not behave this way, showing that the shells died between 3600 to 4400 years B.P, not respecting a uniform precipitation from the oldest to the youngest, but radiocarbon results showed that the first shell layer is older (PM3 $=5900$ years) and the last shell layer is younger (PM1 $=5550$ years), a low age difference. These data results clearly indicated that the ages found in this work are compatible with the historical period (the Holocene period) on the coast of the state of Rio de Janeiro, southeastern Brazil [5].

\section{Acknowledgement}

To FAPESP for financial support - Grant 2017/17116-2 and for Research Internships Abroad - Grant 2018/19950-2 at University of Palermo (UNIPA).

To Department of Engineering of the University of Palermo for irradiation of shells.

\section{References}

1. Ikeya M, Zimmerman MR, Whitehead N (1993) New applications of electron spin resonance: dating, dosimetry and microscopy. World Scientific. Link: http://bit.ly/2Rykfqz

2. Baffa O (1997) O método de datação arqueológica por ressonância paramagnética eletrônica. Rev do Mus Arqueol e Etnol 2: 151-160. Link: http://bit.ly/2vlso95

3. Sullasi HL, Pessis AM (2000) Datação de dentes por espectroscopia rpe fundamentos, metodologia e aplicações. 97-117.

4. Aitken MJ (1985) Thermoluminescence dating. 331-351. Link: http://bit.ly/2TWCpUv

5. Castro JWA, Suguio K, Seoane JCS, Da Cunha AM, Dias FF (2014) Sea-level fluctuations and coastal evolution in the state of Rio de Janeiro, southeastern Brazil. An Acad Bras Cienc 86: 671-683. Link: http://bit.ly/30Z8I6K

6. Castro JWA, Senrab MCE, Ramos RRC (2009) Coquinas da Paleolaguna da Reserva Tauá- Pântano da Malhada, RJ. Um registro de optimum climático holocênico. Sítios Geológicos e Paleontológicos do Bras 515.

7. da Cunha AM, Castro JWA, Dias FF (2012) A importância da preservação das acumulações bioclásticas da Planície Costeira do Rio Una, Municípios de Cabo Frio e Armação dos Búzios, RJ, Brasil. Anu do Inst Geociencias 35: 58 67. Link: http://bit.ly/2Gr9cJw

Citation: Gomes MB, Oliveira LM, Cortez B, D’Oca MC, Tranchina L, et al. (2020) EPR dating of shells from Malhada Marsh, Rio de Janeiro, Brazil. Ann Mar Sci 4(1): 
8. Griscom D (2002) V. B.-L.-A. E. Appl and undefined. ESR Spectra of limestones from the Cretaceous-Tertiary boundary: Traces of a catastrophe.

9. Vichaidid T, Youngchuay U, Limsuwan P (2007) Dating of aragonite fossil shell by ESR for paramagnetic species assignment of Mae Moh basin. Nucl Instruments Methods Phys Res Sect B Beam Interact. with Mater Atoms 262 323-328. Link: http://bit.ly/36p1bPR
10. Durcan JA, King GE , Durcan JA (2015) DRAC: Dose Rate and Age Calculator for trapped charge dating. Quat Geochronol 28: 54-61. Link: http://bit.ly/3aKUgnz

11. Skinner AF (1988) Dating of marine aragonite by electron spin resonance. Quartenaryy Sci Rev 7: 461-464. Link: http://bit.ly/2vtDGs4

\section{Discover a bigger Impact and Visibility of your article publication with} Peertechz Publications

\section{Highlights}

* Signatory publisher of ORCID

* Signatory Publisher of DORA (San Francisco Declaration on Research Assessment)

* Articles archived in worlds' renowned service providers such as Portico, CNKI, AGRIS, TDNet, Base (Bielefeld University Library), CrossRef, Scilit, J-Gate etc.

* Journals indexed in ICMJE, SHERPA/ROMEO, Google Scholar etc.

* OAI-PMH (Open Archives Initiative Protocol for Metadata Harvesting)

* Dedicated Editorial Board for every journal

* Accurate and rapid peer-review process

* Increased citations of published articles through promotions

* Reduced timeline for article publication

Submit your articles and experience a new surge in publication services (https://www.peertechz.com/submission).

Peertechz journals wishes everlasting success in your every endeavours.

Copyright: (C) 2020 Gomes MB, et al. This is an open-access article distributed under the terms of the Creative Commons Attribution License, which permits unrestricted use, distribution, and reproduction in any medium, provided the original author and source are credited.

Citation: Gomes MB, Oliveira LM, Cortez B, D'Oca MC, Tranchina L, et al. (2020) EPR dating of shells from Malhada Marsh, Rio de Janeiro, Brazil. Ann Mar Sci 4(1): 008-013. DOI: https://dx.doi.org/10.17352/ams.000018 